\title{
Assay of Desmopressin in nasal spray by HPLC - UV detector with one Isocratic pump and system set - up
}

\author{
Hazim Hamid Hamdu \\ (Department of Bio - pharmaceutics, Baghdad College of pharmacy/ syndicate of Iraqi pharmacists, iraq)
}

\begin{abstract}
The aim of this study was to apply high performance liquid chromatography - UV detector to determine desmopressin in pharmaceutical preparation using one pump (isocratic pump) and ODS, 5um column. And Mobil phase acetonitrile: $N$, $N$ diethyl formamide in ratio of 85:15 which show good quantitative and qualitative analysis in desmopressin acetate nasal spray (Cipla LTD INDIA) New controlled condition for setting-up the system to get a result with high resolution was shown in this study.
\end{abstract}

Keywords- desmopressin, HPLC method, isocratic pump and system set-up

\section{Introduction}

Desmopressin acetate is a synthetic analogue of natural pituitary hormone 8-arginine vasopressin $(\mathrm{ADH})$ antidiuretic hormone it is chemically defined as fallows.

$\mathrm{S} \mathrm{CH}_{2} \mathrm{CH}_{2} \mathrm{O}$-Tyr-phe-Gln-Asn-Cys-Pro-D-Arg-Gly-NH $\mathrm{N}_{2} . \mathrm{CH}_{3} \mathrm{COOH} .3 \mathrm{H}_{2} \mathrm{O}$

1-(3-mercapto propionic acid) 8-D arginine vasopressin mono acetate (salt) trihydarate

Desmopressin acetate is a large molecule with molecular weight 1183.34 and empirical formula

C46H64N14O12S2.C2 H4O2.3H2O

Also we can conceder desmopressin as poly peptide molecule ${ }^{(1)}$

Desmopressin pharmaceutical preparations available in markets as tablet. powder and spray.

Desmopressin nasal spray can be used in these cases.

1- Vanwillebrands disease (inherited bleeding disorder due to defect in vanwillebrands factor)

2- diabetes insipidus (defect in urine concentration) .

3- hypopituitarism (decreased production of pituitary hormones)

Desmopressin is analogue of vasopressin desmopressin decreased vasopressor activity and increase anti-diuretic activity compare to vasoprossin. ${ }^{(2,3)}$

Desmopressin acetate preparations contain not less than $95 \%$ not more 105\% of Desmopressin .

Many methods for assay of desmopressin were mentioned in Usp ${ }^{(4)}$ like mass spectral analysis and retention time of major peak in chromatogram and specific rotation also microbial assay.

Enumeration test for specified micro organisms of amino acid concentration.

Determine the content of Desmopressin in pharmaceutical preparation by the biological method based on work of brsges and Thoron ${ }^{(5,6,7)}$

Biological activity of Desmopressin estimated by measuring the anti - diuretic effect of studied preparation compare with standard Desmopressin .

The possibility of replacement of biological method which determine the hormonal activity in the pharmaceutical preparation has been created by the introduction of high performance liquid chromatography to the qualitative and quantitative analysis of peptides. ${ }^{(8)}$

In Identification of multiple peptide and proteins (i.e. huge molecules) we must used HPLC with two pumps (binary pump) in order to increase the pressure of the mobile phase tobequite sufficient to more the huge molecules through the column. ${ }^{(9)}$

Jadwiga and wilcgynska ${ }^{(10)}$ use HPLC with two pumps to determine the content of desmopressin in pharmaceutical preparation they performs the assay with mobile phase of $\mathrm{PH}=7$ using column $\mathrm{C} 8.5 \mu \mathrm{m}$ $100 \times 4.6 \mathrm{~mm}$

This encourage use to use new technique in HPLC using one pump in assay of desmopressin by controlling all other HPLC parameters like maximum uv wave length, $\mathrm{PH}$,column, and mobile phase.

1- $\quad$ Specord 40 ( analytike Jena) (USA)

\section{Apparatus:}

2- $\quad$ HPLC KNAUER (Germany) which consist of: 
2.1- Isocratic pump 1000 KNAUER.

2.2- Degasser manager 5000 KNAUER.

2.3- UV detector 2500 KNAUER.

2.4- $250 \times 4.6 \mathrm{~mm}$ Hyperclone $5 \mathrm{u}$ ods (C18) 120 A phenomenex column. (USA)

3- HP-TLC GAMAG (EMERCK KGaA) ( Switzerland)

4- $\quad$ Filler device to produce water for HPLC (Whatman - England)

1- Acetontrile (HPLC grade)

\section{Materials and reagent:}

Gradient $240 \mathrm{~mm}$ for uv scharlab S.L made in Spain.

2- N-N dimethyl formamid for HPLC and spectroscopy Sd fine-CHEM limited MUMBAI-INDIA.

3- Water for HPLC by filter device.

4- $\mathrm{NaOH}$ Sodium Hydroxide. (AVONCHEM limited UK).

5- Desmopressin acetate stander.

Usp reference standard desmopressin acetate.

CAT. No 1173202 usp ROCKVILLE. MD LOT FOE 267.

6- Desmopressin acetate studied sample

Desmopressin acetate Nasal spray $0.01 \%$ w/v Cipla LTD INDIA.

7- Boric Acid (CHEM limited MUMBAI-INDIA).

8- Potassium Chloride BDH England.

\section{Method:}

HPLC (KNAUER) with Isocratic pump (one pump) and (C18) 5u ODS column using Mobil phase of a mixture of acetonitrile and $\mathrm{N}, \mathrm{N}$ diethyl formamid with proportion of $(85: 15)$ respectively of $\mathrm{PH} 10 \pm 0.5$ the assay was carried out at maximum Wave length $230 \mathrm{~nm}$.

The flows Rate of Mobil phase was $2 \mathrm{ml} / \mathrm{mint}$ the sample and the stander of desmopressin acetate have concentration of $0.01 \mathrm{mg} / \mathrm{ml}$.

\section{Preparation of standard solution.}

The content of vial of stander desmopressin acetate was dissolved with water of HPLC to get a concentration of $0.01 \mathrm{mg} / \mathrm{ml}$ of desmopressin acetate.

\section{Preparation of studied sample}

$1 \mathrm{ml}$ of desmopressin spray (contain $0.01 \% \mathrm{w} / \mathrm{w}$ desmopressin acetate) was transferred to $10 \mathrm{ml}$ volumetric flask and completed with water of HPLC to the mark of the flask to get concentration of $0.01 \mathrm{mg} / \mathrm{ml}$ of desmopressin acetate.

\section{Result and calculation}

In assay of desmopressin nasal spray we used HPLC method although desmopressin containing peptide bonds it is not very large molecule like other polypeptieds and proteins this encourages us to use one pump (one Isocratic pump) for the assay with Hyperclone ODS (C18) column this column has a pore size $120 \mathrm{~A}^{\mathrm{o}}$ which is enough for large molecules like desmopressin acetate molecule.

Both chromatographic monographs for stander desmopressin acetate (fig.1) and studied desmopressin acetate (fig.2) show a peak of desmopressin at a retention time of 1.133 mints.

To calculate the percent $(\%)$ of desmopressin in studied sample we used this equation.

$\mathrm{T} / \mathrm{S} * 100=\mathrm{c} \%$

$\mathrm{C} \%=$ desmopressin acetate percent.

$\mathrm{T}=$ Area under the carve for desmopressin studied compound.

$\mathrm{S}=$ Area under the carve for desmopressin in stander.

The average result for $\mathrm{t}=486284$ and the average result for $\mathrm{S}=496171$.

486284

$\mathrm{C} \%=496171 * 100=98 \%$

This result was com play with usp limit ${ }^{(4)}$ to confirm our result to see the validity of this method we used the method used by Jadwige Dudkiewies ${ }^{(10)}$ for determination of desmopressin acetate.

For this procedure we used the same apparatus we used in our experiment with Mobil phase acetonitrile and water in ratio $17: 83$ 
And rate of flow $1.3 \mathrm{ml} / \mathrm{mint}$ and maximum wave length of absorption $\mathrm{Lmax}=220$.

The volume of injection is $20 \mu \mathrm{l}$ with standard and studied material concentration $=0.01 \mathrm{mg} / \mathrm{ml}$ the chromatographic diagram of stander material (fig. 3) and studied material (fig.4) shows desmopressin acetate at retention time of 5.65 mint and 5.75 mint respectively.

$\mathrm{s}$ and $\mathrm{t}$ was calculated which are:

$\mathrm{s}=278548$

$\mathrm{t}=285450$

$\underline{278548}$

$\mathrm{C} \%=285450 * 100=97.5 \%$

This is also comply with usp ${ }^{(4)}$.

\section{Preparation and HPLC system Set - up}

\section{1- Control Maximum wavelength absorption}

In assay of protein or polypeptides we must control all the parameters we used in the assay like the maximum wavelength absorption ( $\mathrm{L}$ max), the $\mathrm{PH}$ of Mobil phase, flow rate and the pressure in pump ${ }^{(9)}$.

L max control and set-up

Desmopressin molecule consists of different amino acid and peptides bonds each amino acid has different $\mathrm{L}$ $\max$ (maximum wave length) of absorption ${ }^{(1)}$ as in table-1.

To set-up our L max for our method of assay we do three experiment

\subsection{Experiment 1}

By using specord 40 (Analytik Jena) we make a transmition scan for stander desmopressin $0.01 \mathrm{mg} / \mathrm{ml}$ for scan mode from 190-300 $\mathrm{nm}$ the diagram of the transmition scan shows high absorption (lower transmition) at ( $\mathrm{L}$ $\max 200-230 \mathrm{~nm}$ ) as shown in (fig.5).

\subsection{Experiment 2}

To see which wave length $200,210,220$ and $230 \mathrm{~nm}$ can give us the best resolution and Isolation for desmopressin we used HP-TLC (CAMAG) using $10 \times 20 \mathrm{~cm}$ TLC plate silica gel $60 \mathrm{~F} 254$ and twin trough chamber $20 \times 20 \mathrm{~cm}$.

Mobil phase acetonitril: $\mathrm{N}, \mathrm{N}$ diethyl formamid in ratio of 85:15 respectively and we make scan to our desmopressin acetate $0.01 \mathrm{mg} / \mathrm{ml}$ stander from $200 \mathrm{~nm}$ wave length to $230 \mathrm{~nm}$ the result shows a best resolution for desmopressin acetate at wave length $230 \mathrm{~nm}$.

(Fig. 6, 7 and 8) shows peak resolution of desmopressin acetate at Lmax $210 \mathrm{~nm}, 220 \mathrm{~nm}$ and $230 \mathrm{~nm}$ respectively.

\subsection{Experiment 3}

Many other experiment for assay of desmopressin they used L max $220 \mathrm{~nm}$ in the assay so to see which $\mathrm{L}$ max is better for our method of assay we run our method for assay of desmopressin one time using L max $220 \mathrm{~nm}$ and another time using $\mathrm{L} \max 230 \mathrm{~nm}$. The higher resolution and the sharp peak of desmopressin was at Lmax 230 $\mathrm{nm}$ (Fig. 1) and the broad peak was at L $\max 220 \mathrm{~nm}$ (Fig. 9) .

\section{2 - control and set-up the PH of Mobil phase.}

As our compound (desmopressin) consist of many amino acid and many peptides bonds and each amino acid has deferent pka ${ }^{(9)}$.

We have to control the $\mathrm{PH}$ of Mobil phase which will give use the best resolution.

Experiment

We prepare alkaline borate buffer solution of PH 8, 9 and 10 .

Method of preparation:

We dissolve $12.37 \mathrm{~g}$ of boric acid and $14.19 \mathrm{~g}$ of potassium chloride $(\mathrm{KCl}$ in water and dilate to $2000 \mathrm{ml}$ to get 2 m solution.

$50 \mathrm{ml}$ of boric acid and $\mathrm{KCl}$ solution in $200 \mathrm{ml}$ volumetric flask we add to it $3.9 \mathrm{ml} 0.2 \mathrm{M} \mathrm{NaOH}$ complete the volume to $200 \mathrm{ml}$ with water for HPLC we get Buffer solution of PH 8 .

And also $50 \mathrm{ml}$ of boric acid $\mathrm{KCl}$ solution in $200 \mathrm{ml}$ volumetric flask and $20.8 \mathrm{ml}$ of $0.2 \mathrm{M} \mathrm{NaOH}$ and complete the volume to $200 \mathrm{ml}$ with water for HPLC to $200 \mathrm{ml}$ we get buffer solution of PH 9 .

Also we add $50 \mathrm{ml}$ of boric acid $\mathrm{KCl}$ solution in $200 \mathrm{ml}$ volumetric flask and add to it $43.7 \mathrm{ml} 0.2 \mathrm{M} \mathrm{NaOH}$ and complete the volume to $200 \mathrm{ml}$ with water for HPLC to $200 \mathrm{ml}$ we get buffer solution of PH 10.

We used these buffer solution as a Mobil phase and we used the same HPLC system we used in our method with flow rate of $1.3 \mathrm{ml} / \mathrm{mint}$ and we inject desmopressin $0.01 \mathrm{mg} / \mathrm{ml}$ stander solution with deferent Mobil phase of different $\mathrm{PH}$ in order to see the high resolution of assay of desmopressin. 
We find that the best peak of height resolution is that when the buffer solution of PH 10 used as Mobil phase. (Fig. 10) shows the peak of desmopressin of PH 9, and (fig. 11) shows the peak of desmopressin at PH 10.

\section{Tables And Figures}

$\begin{array}{cc}\text { Group } & \text { Wavelength }(\mathbf{n m}) \\ \text { Peptide bond } & 190-210 \\ \text { His } & 211 \\ \text { Cys } & 250 \\ \text { Trp } & 280 \\ \text { Tyr } & 274 \\ \text { Phe } & 257\end{array}$

Table -1 absorption bonds in protein (Campbell and Dwek 1984) ${ }^{(11)}$

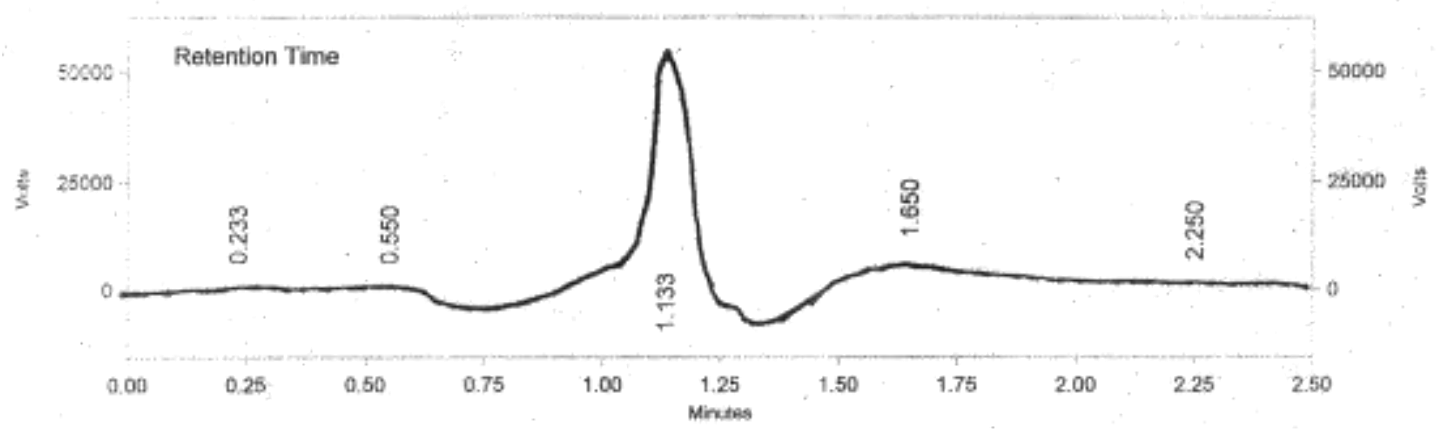

(Fig-1) desmopressin acetate stander

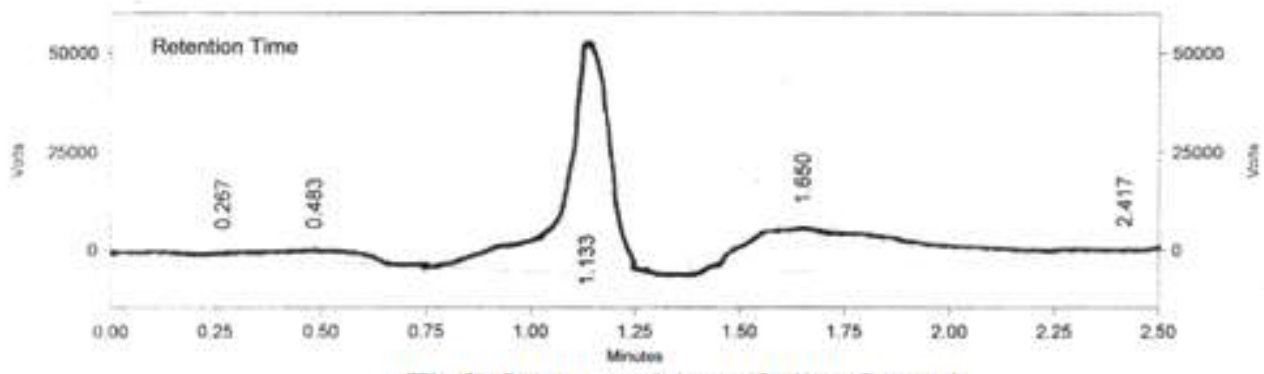

(Fig-2) desmopressin sample (nasal spray)

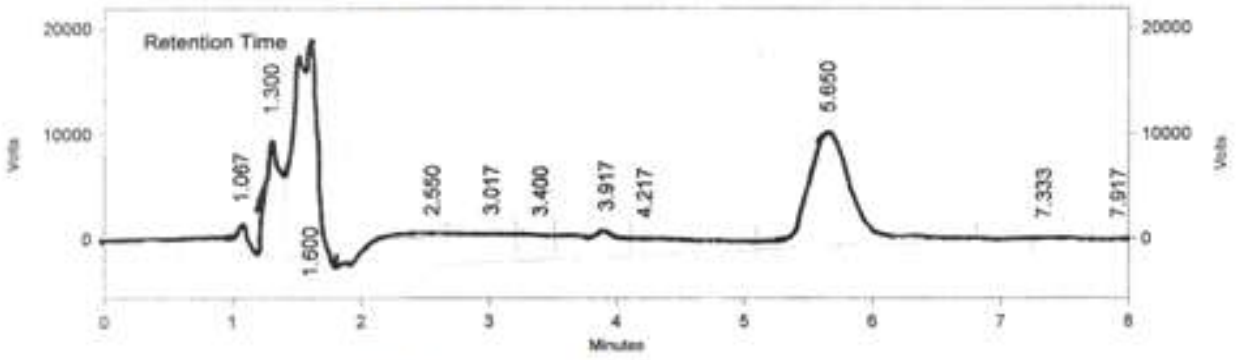

(Fig-3) desmopressin acetate stander

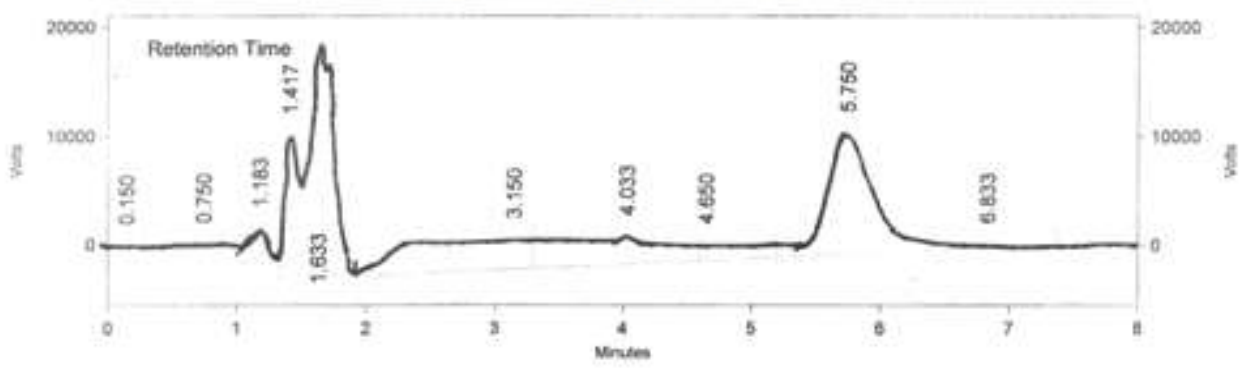

Fig-4 desmopressin Sample (nasal spray) 


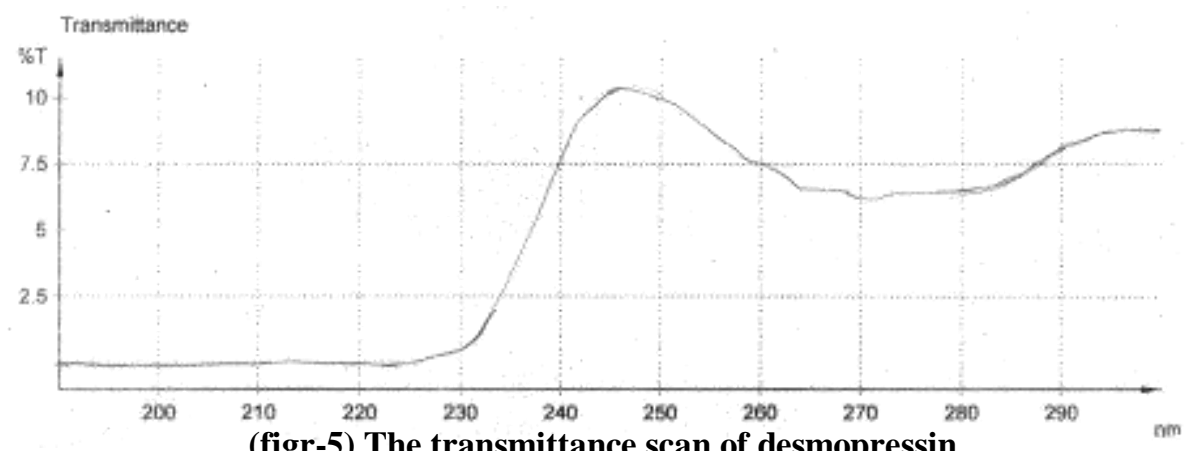

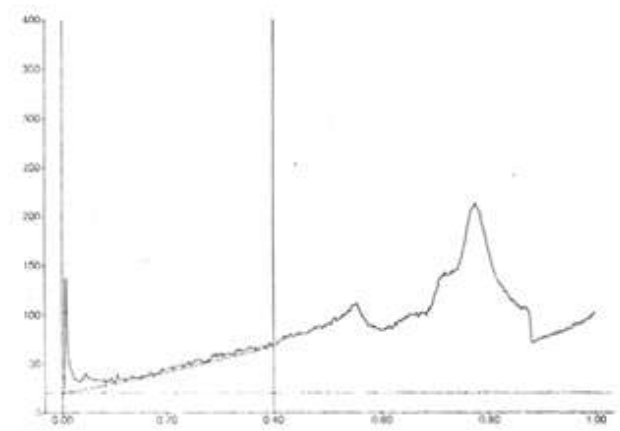

(Fig-6) Absorption at Lmax 210

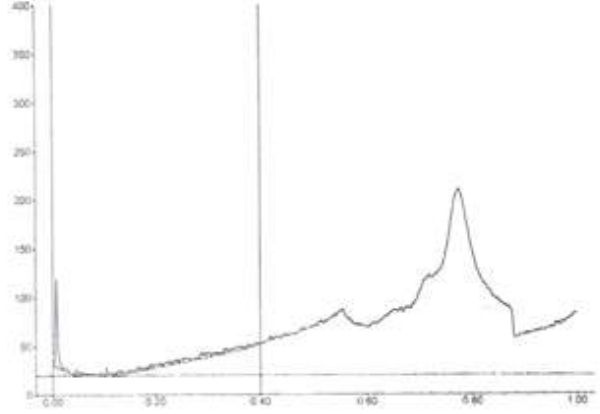

(Fig-7) absorption at Lmax 220

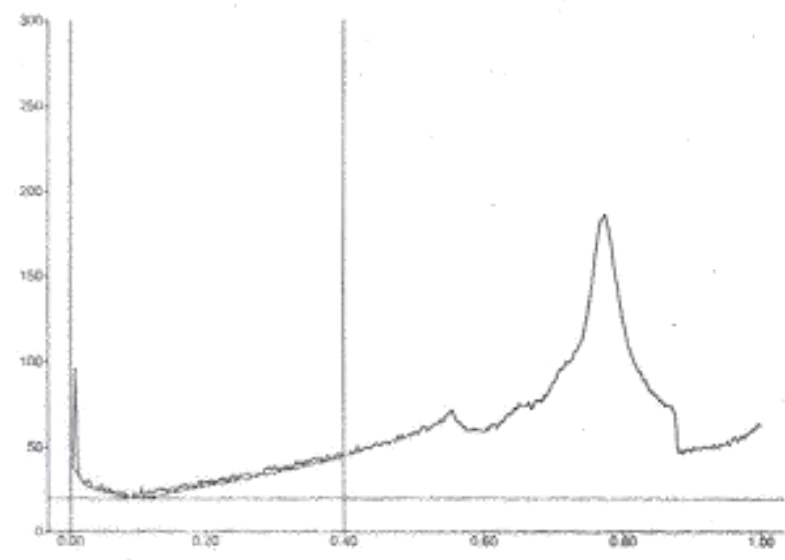

(Fig-8) absorption at Lmax 230

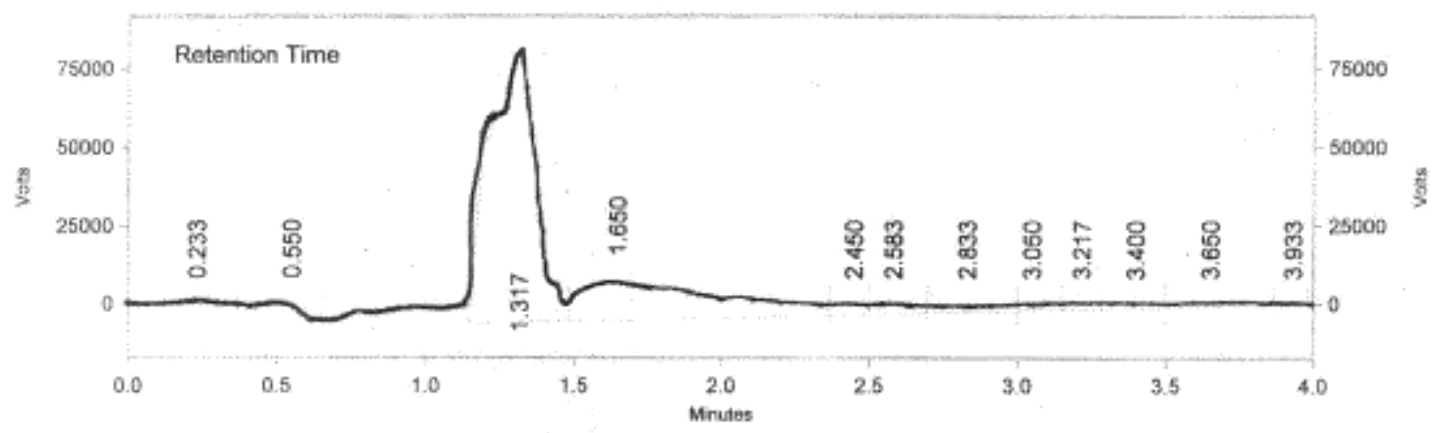

(Fig-9) HPLC diagram for desmopressin at Lmax 220 using acetonitrile: $\mathbf{n n}$ diethyl formamide (Mobil phase) 


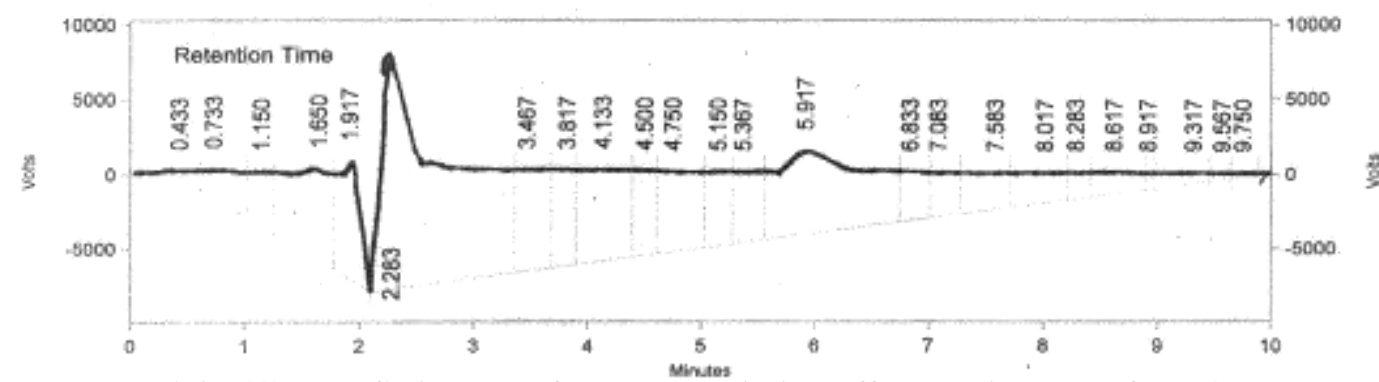

(Fig-10) HPLC diagram of desmopressin in buffer Mobil phase of PH-9

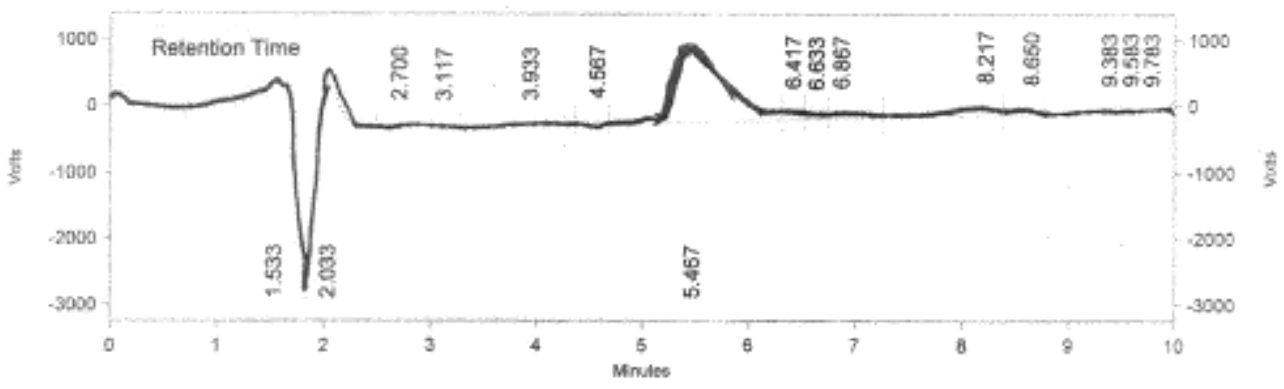

(Fig-11) HPLC diagram of desmopressin using Mobil phase buffer PH-10

VIII. Discussion \& Conclusion

As we increase the percent of acetonitrile in Mobil phase the pressure in the purp will be decreases(8) so we increase the percent of acetonitrile in our experiment to $85 \%$ to get reduced in pressure.

This can help as to use one pump instead of two pumps to move the large molecules of desmopressin through our column with $120 \mathrm{~A}^{\mathrm{o}}$ pores.

In our experiment we used the Mobil phase of acetonitrile: N,N diethyl formamide (85:15) this proportion give as the benefit over other HPLC methods.

1- The PH of this Mobil phase is 10 and as we see in PH set-up we get a best resolution in PH 10.

2- Reduced the pressure in our HPLC pump to $40 \mathrm{Mpa}$ so we can use only one pump (Isocratic pump) instead of two pumps to move the large molecules of desmopressin through our column with $120 \mathrm{~A}^{\mathrm{o}}$ pores.

3- Redaction of the pressure in pump make it easy to increase the rate of flow so the retention time will be short this can reduce the time of experiment and the loss of Mobil phase as we see in (fig.1,2,3,4).

In our new method of assay we can used less concentration of stander and tested material because this methods is very sensitive and of high resolution.

We can use in our method desmopressin consent ration of $0.01 \mathrm{mg} / \mathrm{ml}$. While other method we used concentration not less than $0.25 \mathrm{mg} / \mathrm{ml}$ of desmopressin.

Although the Mobil phase in our method is expensive but we need less volume of Mobil phase, that the result to be achieved because we have less retention time for desmopressin acetate.

\section{References}

[1] Sanofi - Aventis DDAVP (Desmopressin acetate) nasal spray prescribing information Bringwater, NJ; 2007 Jul.

[2] JE Kaufmann, A Oksche, CB Wollheim. Vasopressin - induced von willebrand factor secretion from endothelial cells in volves V2 receptor and c AMP. Jclin invest . 2000 Jul, 106(1); 107-116.

[3] L Bagher, T ozra, S Akbar. Comparison of desmopressin (DDAVP) tablet and intranasal spray in the treatment of diabetes insipidus Daur 2005; Vol 13. No 4 page 155.

[4] USP 32-NF 27 page 35 pharmacopial form; volume no. 34(6) page1531.

[5] GL Robertson, EA Mahr, S Athar. Development and clinical application of anew method for the radio immunoassay of arginine vasopressin in human plasma. J clin. Invest. 1973 sep, 52(9): 2340-2352

[6] TE Bridges, NA Thorn. The physiology of vasopressin release and the pathogenesis of imparedwater excretion in adrenal thyroid and edematous dis order. J Endocr.1979; 48, 265

[7] E Ilan, S Aqmselem, M Weisspapir. Improved oral delivery of desmopressin via a novel vehicle: mmcoadhesire Submicron emulsion. Pharm Res. 1996; 13(7): 1083-7

[8] I.B Reinhard, TW Milton. Curvent protocols in molecular biology. (2001) 10.12.1-10.12.9 (copy right 2001 by John Wiley and sons inc).

[9] W Mathnias, K Roland, H Klaus. Insect biochemistry and moleculere biology. 2000; (30). 711-718.

[10] D.W Jadwiga, A Wileznska, S Andrzej. Determination of the content of desmopressin in pharmaceutical preparations by HPLC and validation of the method. Actapoloniac pharmaceutica - Durg Research 59(3), 2002 PP.163-168.

[11] ID Campbell, RA Dwek. Biochemistry and molecular biology education, (PP 404 Addison Wesley, wokinghan UK. April 1985) vol. 13 Issue 2 page 49-96. 